\title{
Coherent GNSS Reflections over the Sea Surface: A Classification for Reflectometry
}

M. Semmling ${ }^{1,2}$, S. Gerland ${ }^{3}$, T. Gerber ${ }^{1}$, M. Ramatschi ${ }^{1}$ G. Dick ${ }^{1}$, J. Wickert ${ }^{1,4}$, M. Hoque ${ }^{2}$

German Research Centre for Geosciences GFZ, Potsdam, Germany

2 German Aerospace CenterDLR-SO, Neustrelitz, Germàny

3 Norwegian Polar Institute NP, Tromsø, Norway

${ }^{4}$ Technische Universität Berlin, Germany

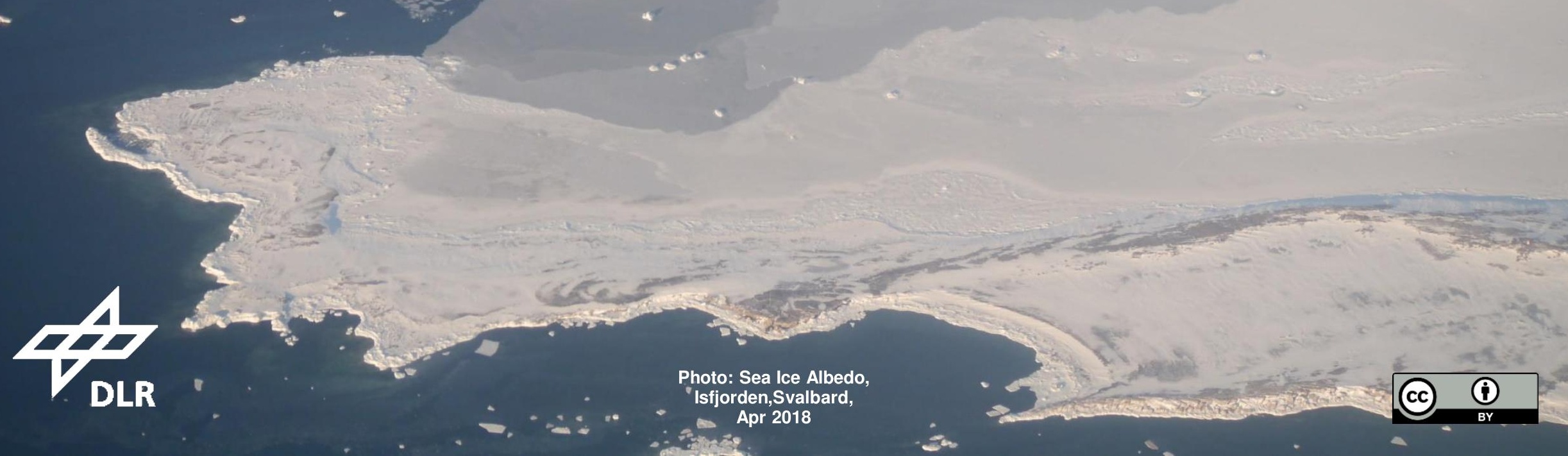




\section{Motivation Climate Studies}

1. Sea ice influences climate through the Earth's radiation budget, ice-covered sea surface throws back more radiation than open-water

2. Sea ice is also an indicator of changing climate, its monitoring is crucial in this respect

3. The Marginal Ice Zone (MIZ), where sea-ice and open-water coincides, is challenging for remote sensing

Important surface properties (SP) can be obtained from GNSS reflectometry. They can contribute to climate investigations and help to study sea ice in the MIZ.

The next slide lists surface properties and shows their relation to the Earth's radiation budget. 


\section{Motivation Climate Studies}

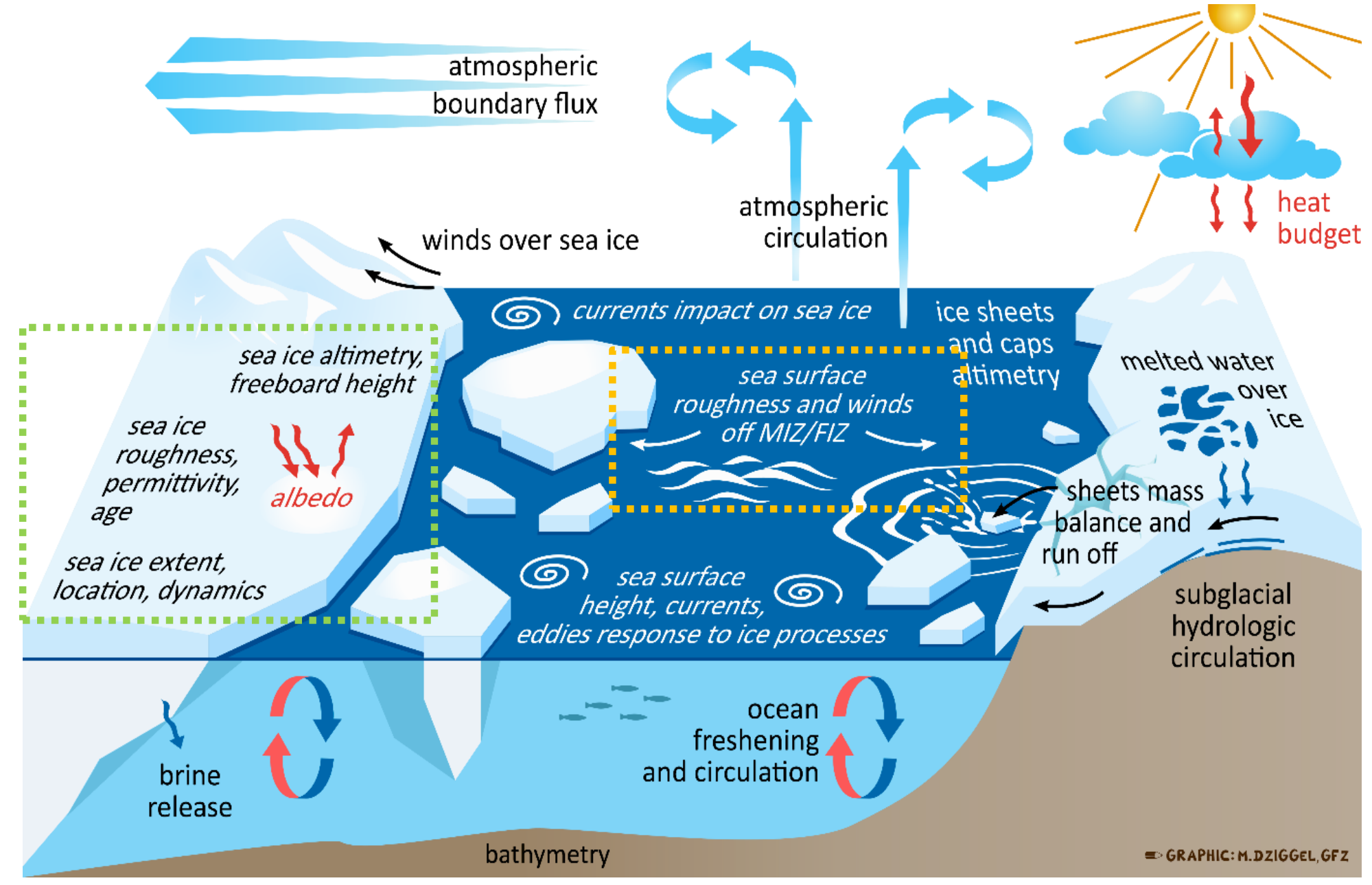

Figure: Cardellach et al. 2018

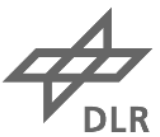




\section{Objectives}

1. GNSS signal amplitude and carrier phase observations shall be used for remote sensing in ship-based measurements with emphasis on sea-ice.

2. Coherence of reflected signals is important for carrier phase retrievals. The sea state and sea ice conditions for coherent reflection shall be assessed.

3. The ionospheric effect on the signal amplitude in ship-based measurements shall be assessed as well. 


\section{Lance Measurements}

Since 2016 GFZ and NPI run a cooperation focusing on sea-ice reflectometry based on research vessels (R/V). Measurements on R/V Lance ${ }^{1}$ have been realized during expeditions in Fram Strait 2016 and 2017.

GNSS reflectometry hardware:

GORS receiver,

RHCP master antenna (up-looking),

LHCP/RHCP slave antenna (port-side-looking)

cf.: Peraza et al. 2017,

Semmling et al. 2019

Setup location on ship:

Crow's nest, starboard view (2016), front view (2017)

Antennas $\sim 24 \mathrm{~m}$ above sea level

1 former Norwegian research vessel with ice class, in service until 2017

${ }^{2}$ passage between Greenland and Svalbard, roughly between $77^{\circ} \mathrm{N}$ and $81^{\circ} \mathrm{N}$

DLR 


\section{Lance Measurements}

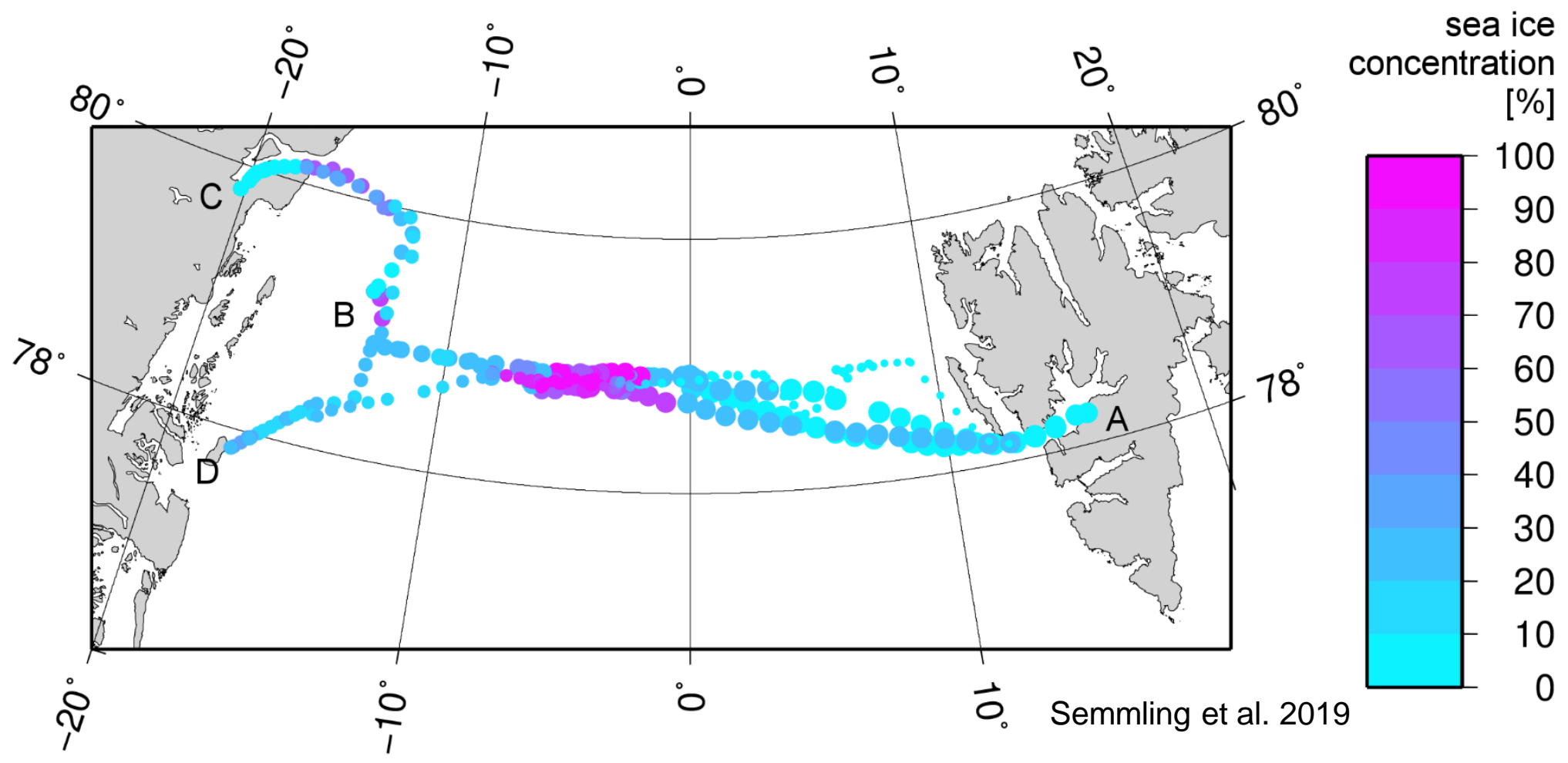

B: stations at fast ice

8 days

A: start Longyearbyen, Svalbard (25/08/2016) 5 days

C/D: stations at Greenland coast $\longrightarrow$ A days $\longrightarrow$ A: end Longyearbyen, Svalbard (13/09/2016)

13.4 days (out of 20 ) with significant sea-ice concentration (> $10 \%$ ) 


\section{Lance Measurements}

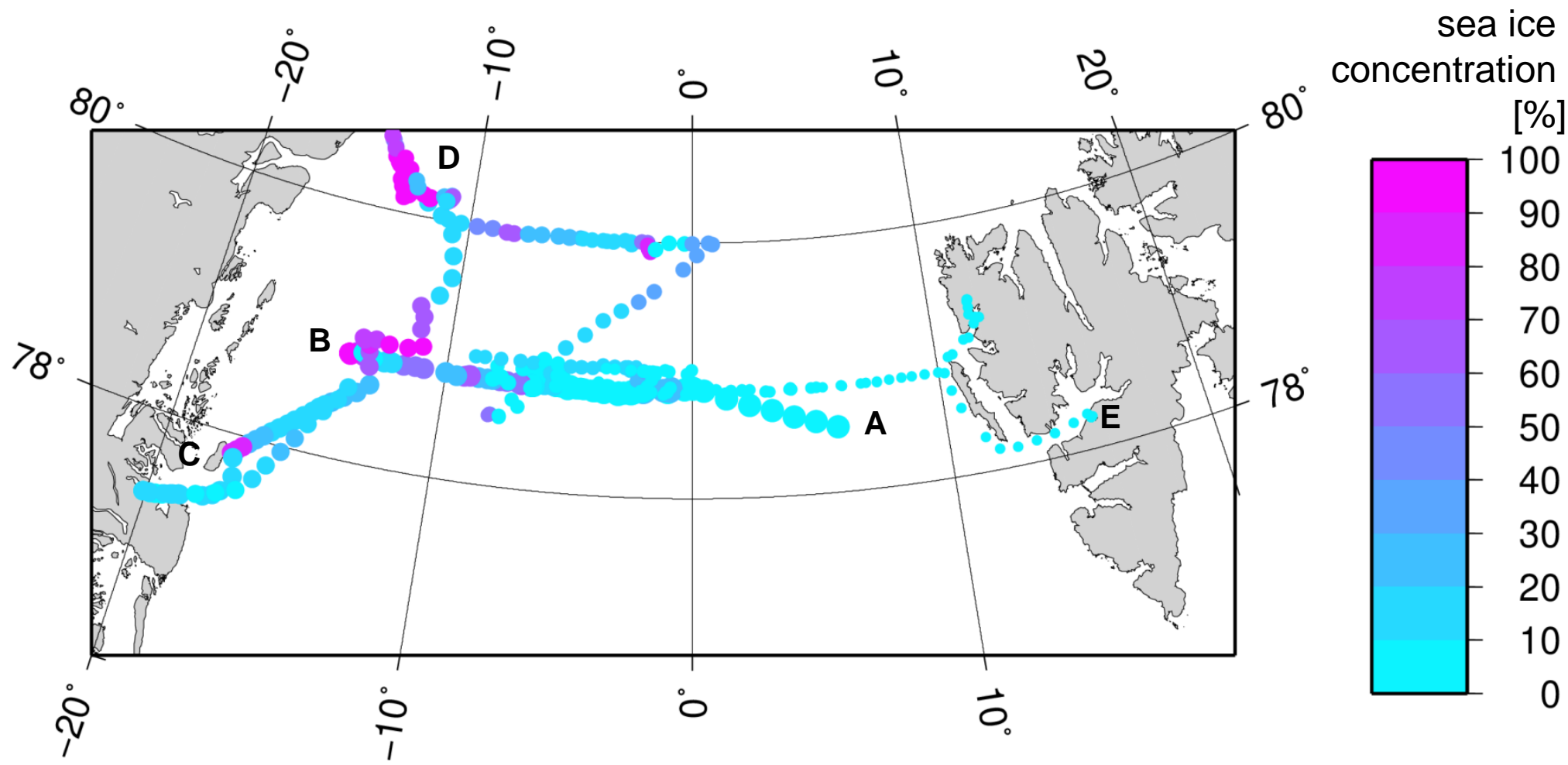

B: stations at fast ice

6 days

A: start Eastern Fram Strait (25/08/2017)

4 days

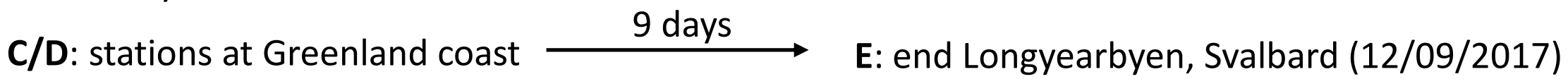

5.6 days (out of 19) with significant sea-ice concentration (> 10\%) 


\section{Polarstern Measurements}

In 2019 GFZ joined the MOSAiC ${ }^{1}$ project to run GNSS remote sensing measurements during the Arctic Drift of R/V Polarstern². A combined setup for GNSS atmosphere sounding and GNSS reflectometry was installed.

GNSS reflectometry hardware:

GORS receiver,

RHCP master antenna (up-looking),

LHCP/RHCP slave antenna (port-side-looking)

cf.: Peraza et al. 2017,

Semmling et al. 2019

Setup location on ship:

Observation deck, port side

Antennas $\sim 22 \mathrm{~m}$ above sea level

${ }^{1}$ Multidisciplinary drifting Observatory for the Study of the Arctic Climate

${ }^{2}$ German research vessel with ice class, in service since 1982 


\section{Polarstern Measurements}

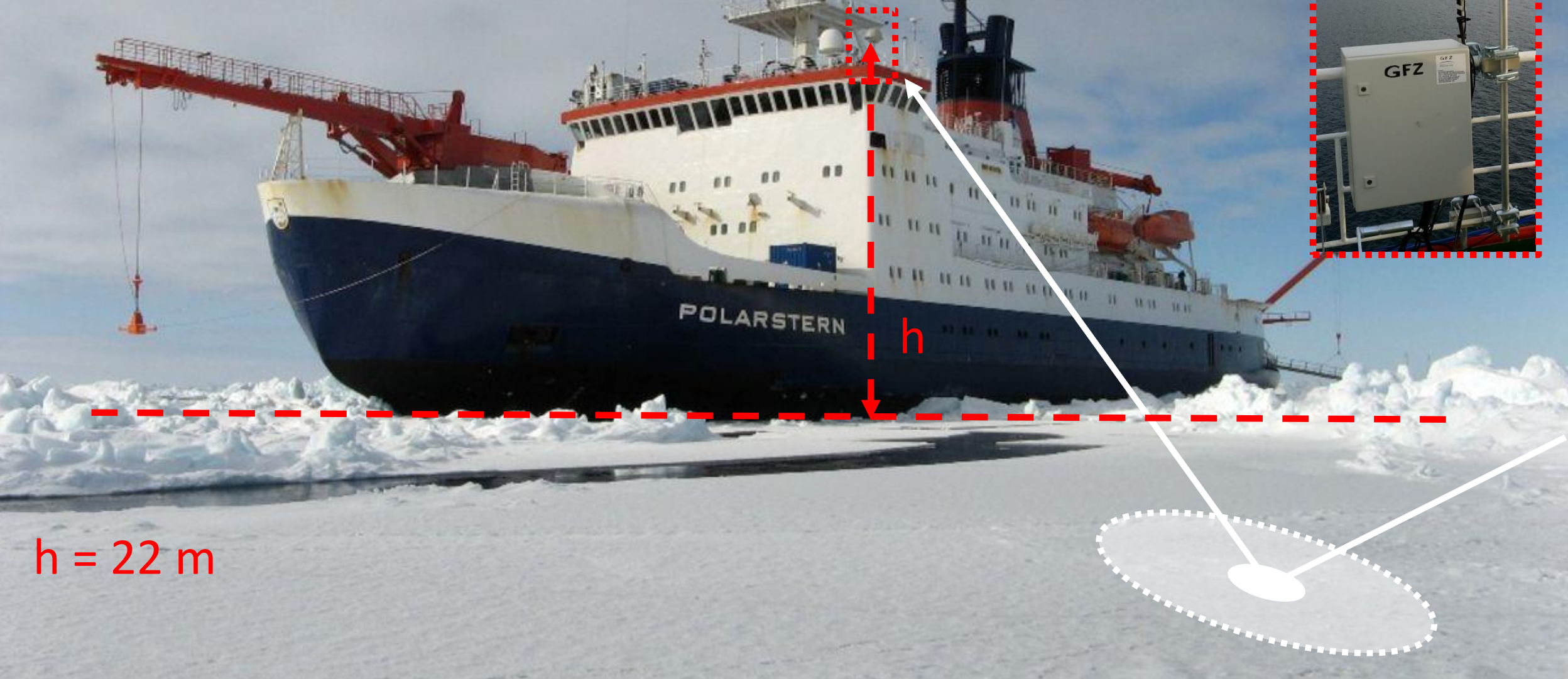




\section{Polarstern Measurements}

Selected data set (1 month) out of 18month expedition:

A: expedition start in Troms $\varnothing$ (20/09/2019)

B: ice floe found for drift (01/10/2019)

C: begin of selected data set $(01 / 11 / 2019)$

30 days sea-ice drift

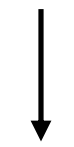

D: end of selected data set (30/11/2019)

30 days with

high sea-ice concentration (> $80 \%$ )

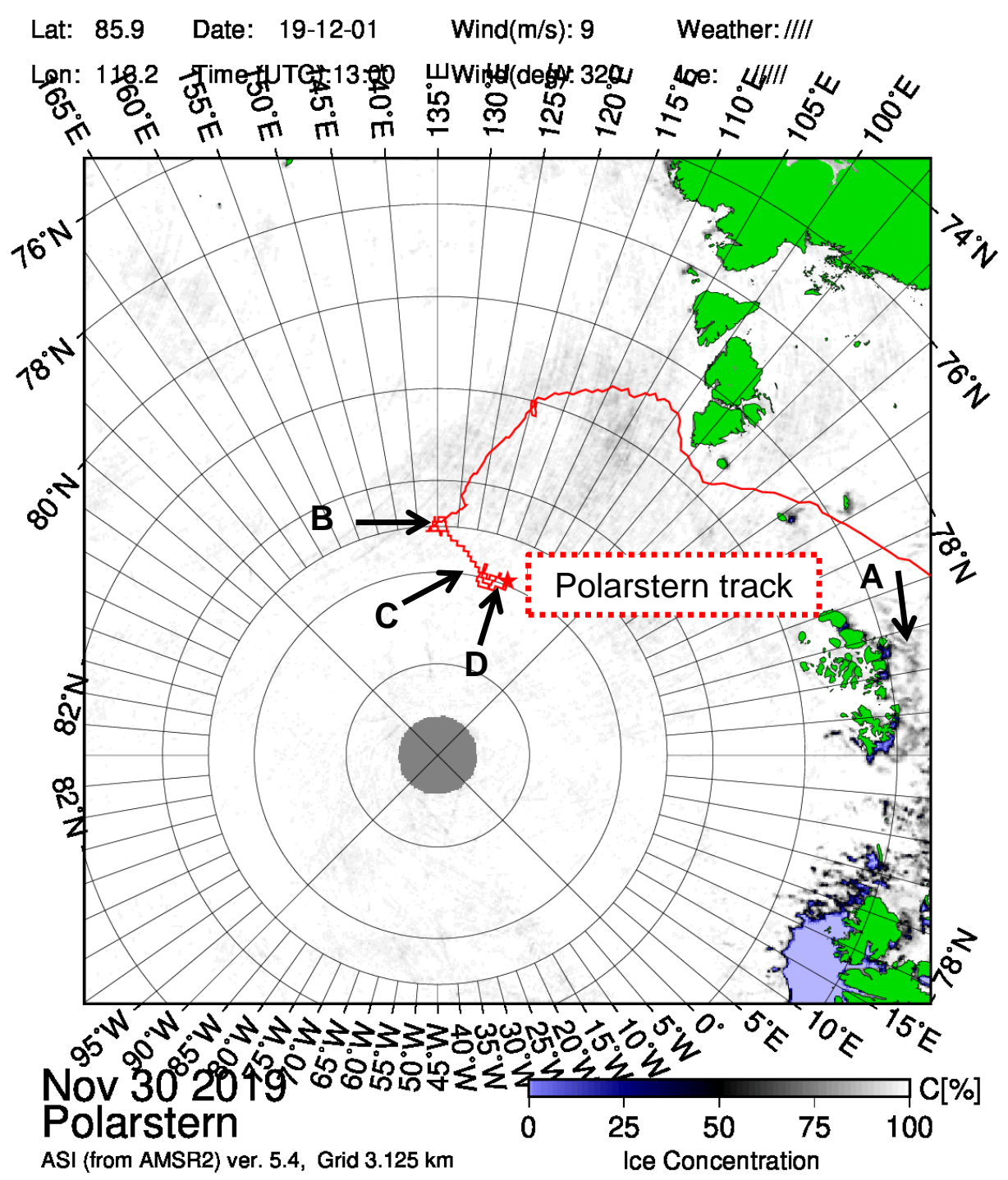

Source: https://seaice.uni-bremen.de/databrowser/ 


\section{Signal Coherence Retrieval}

A retrieval of sea ice concentration using ship-based GNSS reflectometry has been demonstrated using data from the 2016 Fram Strait expedition [Semmling et al. 2019].

Here we follow this retrieval up to data level (1) of estimated reflection power. We apply it for all three data sets. A short summary of processing steps:

- Coherent Processing of master and slave antenna signals

- Signal Separation to retrieve direct and reflected signal contributions

- Power Estimation for coherence classification using signal-to-noise ratios

The important final step is to apply a coherence condition:

$$
\text { SNR }>30 \mathrm{~dB}
$$

Based on phase altimetry simulations in Semmling et al. [2016]

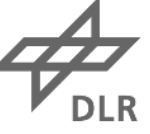




\section{Sea State Estimation}

It was found that the noise level in the coherent processing increases if the ship navigates through a rough sea. The noise level is lower when the sea is calm due to the presence of sea ice [Semmling et al. 2019].

According to the objectives: coherent reflection conditions shall be assessed dependent on sea state and sea ice concentration.

The sea ice concentration is obtained from ancillary data as shown above. The sea state can be described by the Significant Wave Height. However, this parameter is not easily found in the vicinity of sea ice.

It is assumed here that variations of the ship's vertical velocity are directly related to the sea state. The stand. dev. of the vert. vel. is determined and used as sea state parameter. 


\section{Preliminary Results Fram Strait 2016}

master channel:

$\mathrm{n}$ : fraction of coherent obs.

$\mathrm{n}_{\mathrm{d}}: \ldots$ for direct signal

$n_{r}: \ldots$ for reflected signal

slave channels:

$\mathrm{n}$ : fraction of coherent obs.

$n_{r}: \ldots$ for refl. signal RHCP +

$n_{r}$ : ... for refl. signal LHCP $\quad x$
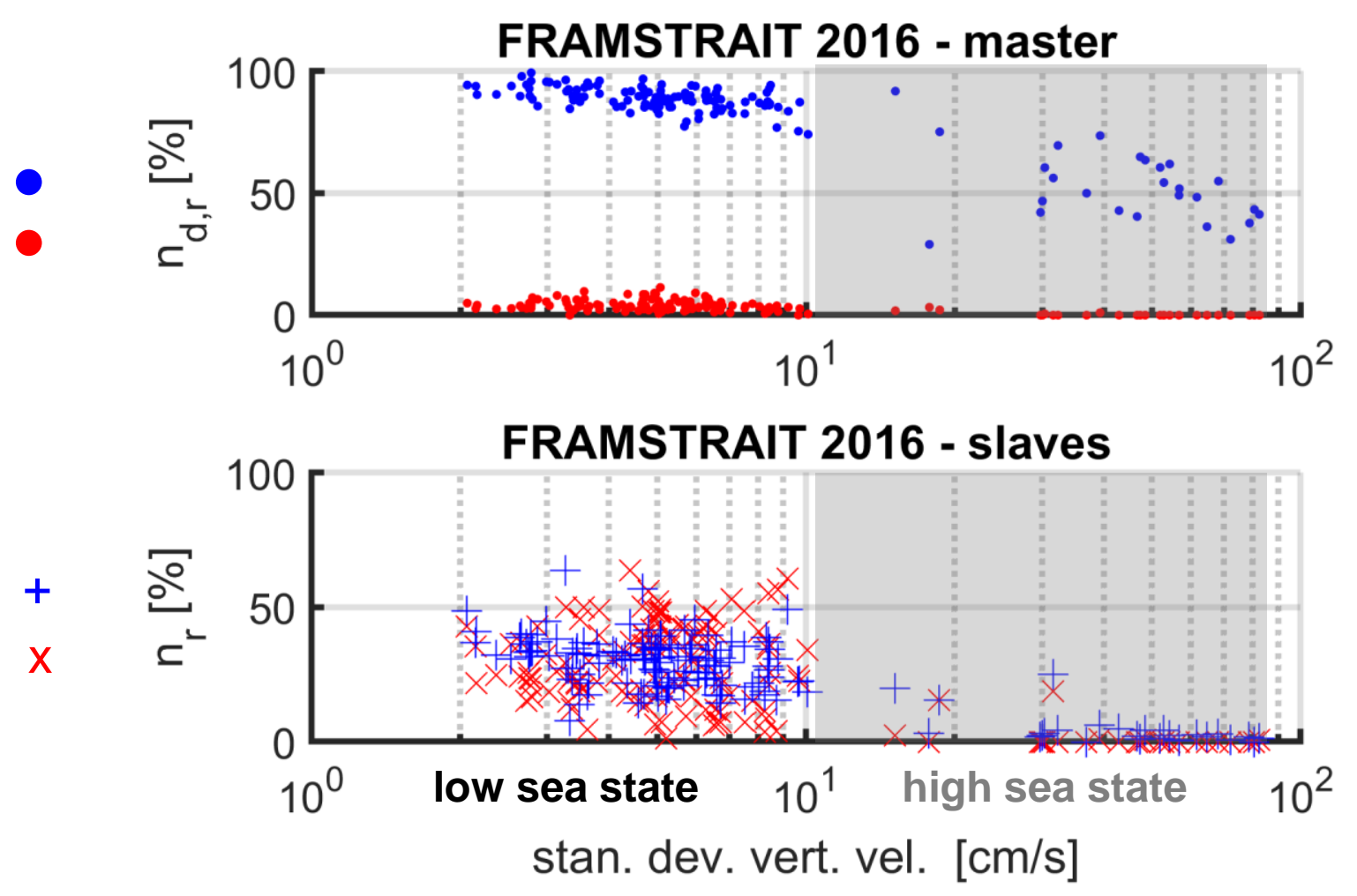

Data amount in days:

14.5

3.6 


\section{Preliminary Results Fram Strait 2017}

master channel:

$\mathrm{n}$ : fraction of coherent obs.

$\mathrm{n}_{\mathrm{d}}: \ldots$ for direct signal

$n_{r}:$... for reflected signal

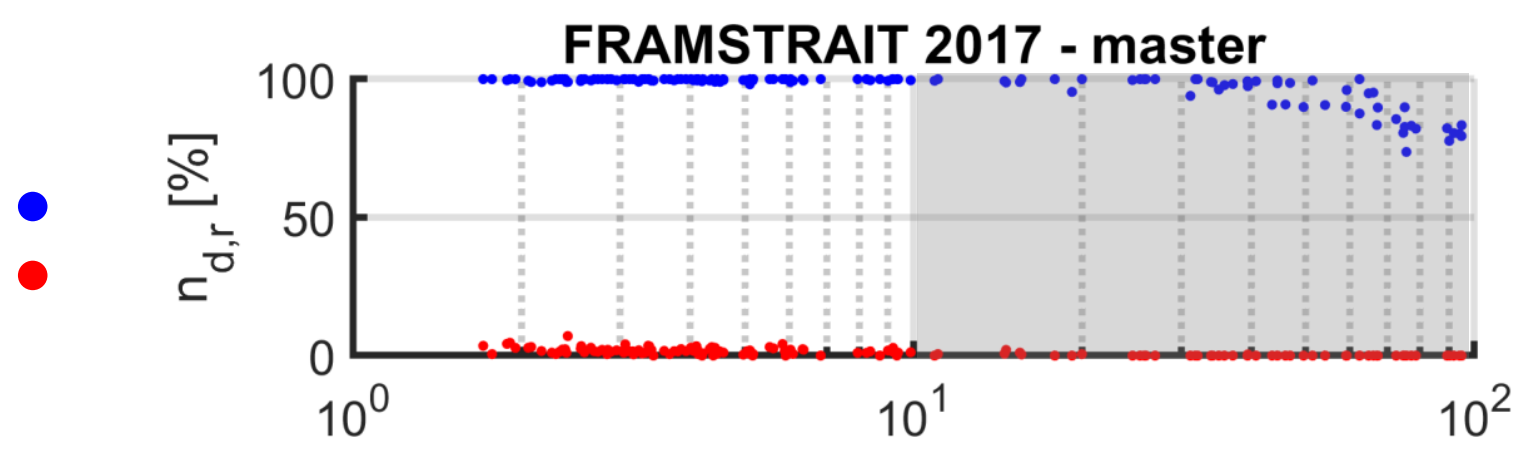

slave channels:

$\mathrm{n}$ : fraction of coherent obs.

$n_{r}$ : ... for refl. signal RHCP +

$n_{r}:$... for refl. signal LHCP $\quad x$

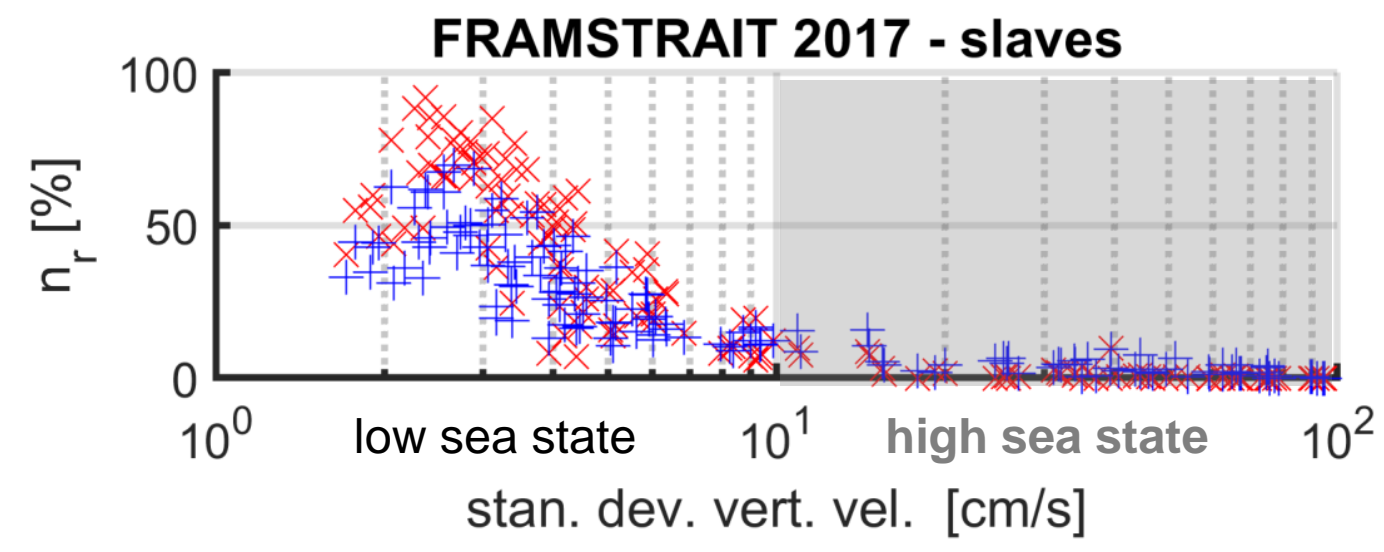

Data amount in days:

11.1

7.0

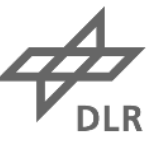




\section{Preliminary Results MOSAiC Nov. 2019}

master channel:

$\mathrm{n}$ : fraction of coherent obs.

$\mathrm{n}_{\mathrm{d}}: \ldots$ for direct signal

$n_{r}: \ldots$ for reflected signal

slave channels:

$\mathrm{n}$ : fraction of coherent obs.

$n_{r}$ : ... for refl. signal RHCP +

$n_{r}$ : ... for refl. signal LHCP $\quad x$
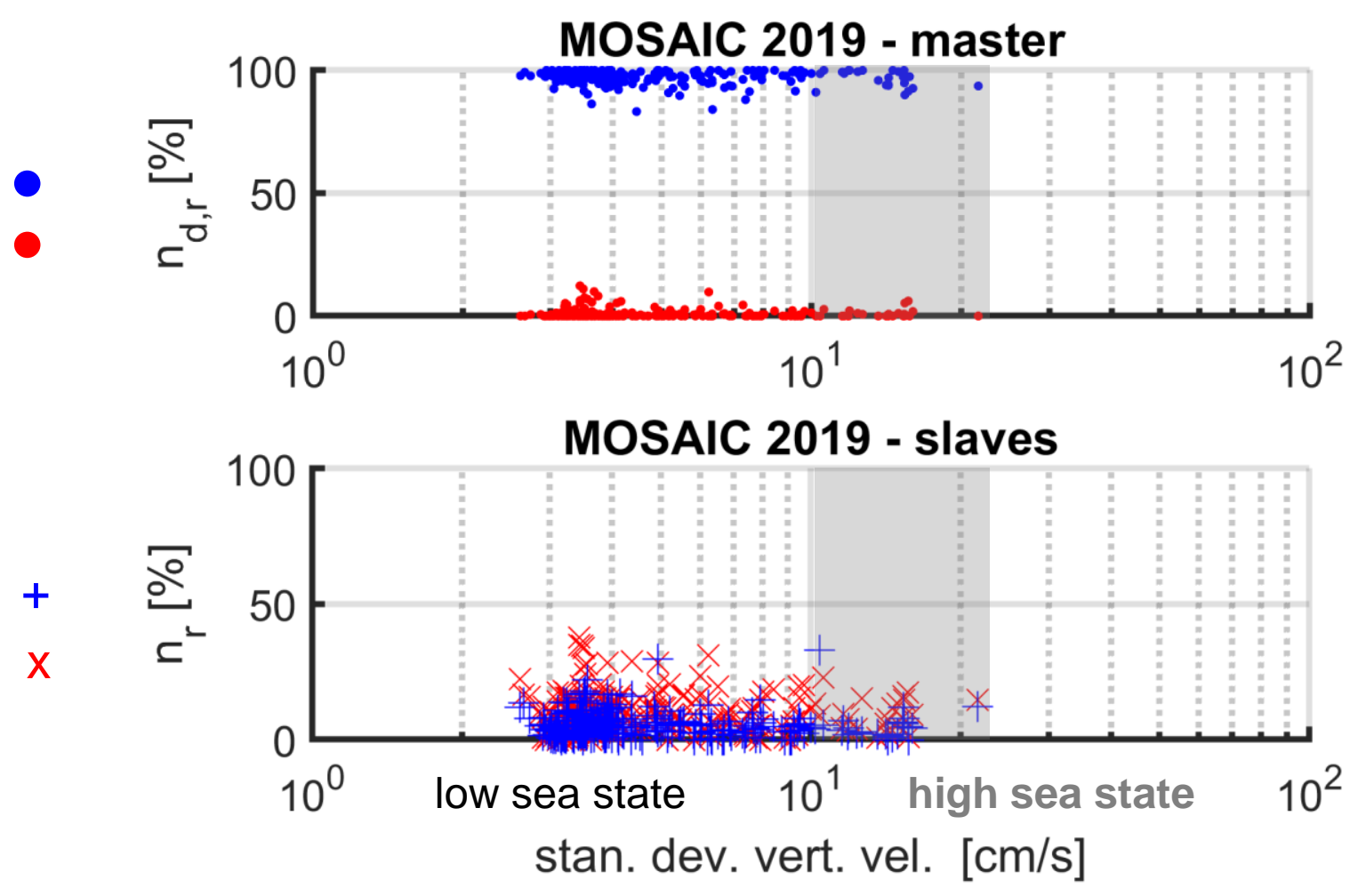

Data amount in days:

26.9 


\section{Summary Coherence Classification}

\begin{tabular}{|l|l|l|l|}
\hline & Fram Strait 2016 & Fram Strait 2017 & MOSAiC 2019 \\
\hline Data in days & $14.5^{1}(3.6)^{2}$ & $11.1(7.0)$ & $26.9(3.1)$ \\
\hline Average $\mathrm{n}_{\mathrm{d}}$ (master) & $89 \%(52 \%)$ & $100 \%(92 \%)$ & $97 \%($ n.s.) \\
\hline Average $\mathrm{n}_{\mathrm{r}}$ (master) & $4 \%(0 \%)$ & $2 \%(0 \%)$ & $1 \%($ n.s.) \\
\hline Average $\mathrm{n}_{\mathrm{r}}$ (left) & $30 \%(3 \%)$ & $45 \%(1 \%)$ & $10 \%($ n.s.) \\
\hline Average $\mathrm{n}_{\mathrm{r}}$ (right) & $30 \%(5 \%)$ & $33 \%(3 \%)$ & $5 \%($ n.s.) \\
\hline Signif. sea-ice & on 13.4 days & on 5.6 days & on 30.0 days \\
\hline
\end{tabular}

${ }^{1}$ values in black: low sea state

${ }^{2}$ values in gray: high sea state 


\section{Conclusions}

- Ship-based Measurements

- realized on R/V Lance and R/V Polarstern in Arctic scenarios

- in general high fraction of coherent obs. for direct signals

- coherent fraction significantly lower for reflected signals

- Effect of Sea State and Sea Ice

- coherent reflections vanish for high sea states

- sea ice coincides with low sea states and improve coherent conditions

- Further Effects

- comparability of the different ship setups is limited

- effect of different visibility and multipath conditions to be investigated

- ionosphere effects not yet considered 


\section{References}

- Semmling et al. 2016: A phase-altimetric simulator: studying the sensitivity of Earth-reflected GNSS signals to ocean topography. IEEE Trans. Geosci. Remote Sens.

- Peraza et al. 2017: Analysis of Grazing GNSS Reflections Observed at the Zeppelin Mountain Station, Spitsbergen. Radio Science.

- Cardellach et al. 2018: GNSS Transpolar Earth Reflectometry exploriNg System (G-TERN): Mission Concept. IEEE Access

- Semmling et al. 2019: Sea Ice concentration derived from GNSS reflection measurements in Fram Strait. IEEE Trans. Geosci. Remote Sens. 


\section{Acknowledgements}

Science Team \& Crew of NPI Fram Strait Expeditions

Science Team in MOSAiC project Logistics at AWI \& Crew of R/V Polarstern Werkstatt des GFZ Geodäsie Department.

Data used here was produced as part of MOSAiC project.

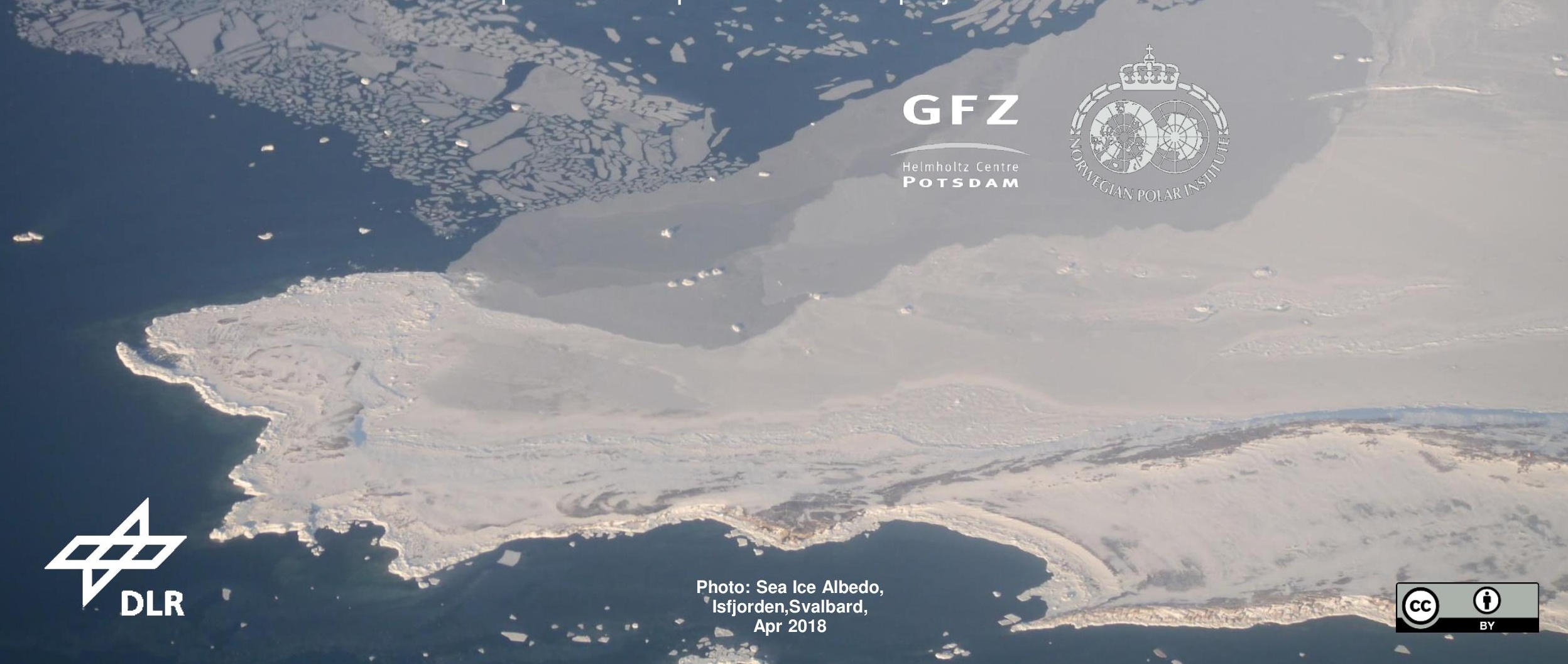

